DOI 10.37882/2223-2982.2020.05.23 \title{
ПРЕИМУЩЕСТВА СМЫСЛОВОГО МЕТОДА ДЛЯ ОБУЧЕНИЯ ВЗРОСЛЫХ УЧАЩИХСЯ ЧТЕНИЮ НА ИНОСТРАННОМ ЯЗЫКЕ
}

\section{ADVANTAGES OF THE SEMANTIC METHOD FOR TEACHING READING IN A FOREIGN LANGUAGE TO ADULT LEARNERS}

\section{E. Nenyuk}

Summary: This article is devoted to the peculiarities of the semantic method recommended for teaching reading in a foreign language in the classes with adult students. This method was developed on the basis of well-known methods that are used for teaching language to different categories of students. Three fundamentally different approaches were analyzed: whole word, phonics, and whole language methods. The research showed that some methods for teaching reading in the native language are applicable for learning foreign languages. These methods are practiced only when working with children. The article presents arguments in favor of their use in classes with adults as well. The article provides examples of various techniques for teaching reading, and shows their effectiveness. In addition, various strategies for teaching reading depending on the goal set are described.

Keywords: semantic method, phonics, whole language method, whole word method, decoding, immersion method, reading comprehension, reading techniques, effectiveness, adult learners, extensive and intensive reading, reading fluency.
$\mathrm{O}$ бычно мы не помним, как научились говорить на родном языке, при этом процесс обучения чтению остается в памяти. Хотя эти навыки связаны друг с другом, способы их приобретения сильно различаются. Это объясняется тем, что мы заговариваем естественным путем, имитируя звуки и звукосочетания. В то время, как в процессе обучения чтению участвуют дополнительные инструменты, как-то - знаковая система, которую необходимо освоить. Во-многом, изучение иностранных языков базируется на тех же принципах.

Лингвистами и педагогами было предложено много различных методов обучения чтению, но ни один метод не был признан оптимальным. «До сих пор, горячие споры о наиболее подходящей форме обучения чтению продолжают поляризовать педагогическое сообщество».[1, с.7]. Проанализированные нами результаты исследований выявляют как позитивные стороны различных методик, так и те аспекты, которые могут мешать приобретению навыков чтения.
Ненюк Евгения Абрамовна

Ph.D in Linguistics, старший преподаватель, Финансовый университет при Правительстве РФ, г. Москва janna_tev@hotmail.com

Аннотация: Данная статья посвящена особенностям смыслового метода, рекомендуемого для занятий со взрослыми учащимися в процессе обучения чтению на иностранном языке. Данный метод был выработан на основе известных методов, которые используются в преподавании языка разным категориям учащихся. Были рассмотрены три принципиально разных подхода: пословный, фонетический и метод целого текста. Также в процессе исследования было отмечено, что некоторые методики обучения чтению на родном языке применимы для изучения иностранного языка. Речь идет о методах, которые практикуются только при работе с детьми. В статье приведены аргументы в пользу их применения на занятиях со взрослым контингентом. В статье приводятся примеры разнообразных техник обучения чтению, и показывается их эффективность. Наряду с этим описываются различные стратегии обучения чтению в зависимости от поставленной цели.

Ключевые слова: смысловой метод, фонетический, метод целого текста, пословный метод, расшифровка, метод погружения, понимание прочитанного, техники чтения, эффективность, взрослые учащиеся, экстенсивное и интенсивное чтение, беглость чтения.

Были рассмотрены три принципиально разных подхода. При первом, так называемом пословном методе, дети учатся распознаванию и запоминанию отдельных слов. Здесь используются средства, помогающие одномоментно распознавать от 50 до 100 слов. Следующая порция слов изучается по аналогии. В качестве примера может служить модель китайского языка, в котором каждому символу в письменном языке соответствует слово или корень слова.

Интересно, что последние полвека в самом Китае придерживаются обратной методики: в качестве первого шага к грамотности студентов учат читать китайские слова с помощью латинского алфавита. Точно так же носители большинства других языков изучают взаимосвязь между буквами и ассоциированными с ними звуками (фонемами). Иными словами, детей учат, как использовать свои знания алфавита для озвучивания слов. Эта процедура определяет второй подход к обучению чтению - фонетический. 
Связь между буквами и фонемами на первый взгляд выглядит достаточно просто. Например, буква «b» почти всегда обозначает звук, как в слове «bat». Или же глухое «е», означает, что предшествующий гласный звук длинный, как в словах «pave», «save». Хотя финальное «е» не озвучено, его роль определена. Английский язык, однако, предлагает множество исключений, как, например, слово «here». Такие проблемные, но распространенные слова ребенок должен выучить в числе первых.

Расшифровки соответствия между буквами и фонемами облегчают развитие навыков чтения у детей разного возраста, способностей, находящихся в разных социально-экономических условиях. Хотя фонетические подходы применительно к взрослым и подросткам мало изучены, они широко практикуются при изучении иностранных языков.

Обучение чтению с помощью букв и фонем можно условно назвать расшифровкой. Время, которое преподаватель должен посвящать проблеме расшифровки иностранных слов, зависит от того, насколько развиты базовые языковые навыки у каждого учащегося. Например, взрослым, которые имеют хорошую теоретическую базу в родном языке, и изучают английский как второй язык, может потребоваться меньше времени для приобретения практических навыков расшифровки английских слов.

Владение словарным запасом - это не просто путь от незнания к знанию значения слова. Скорее, знания учащихся развиваются на непрерывной основе, которая варьируется от незнания слова вообще до его распознавания, а затем - знания его использования в различных контекстах. Поскольку словарный запас имеет тенденцию расти с опытом чтения, взрослым рекомендуется практиковать чтение широкого спектра контента, включая тексты, связанные с их образованием, профессиональной деятельностью, или другими конкретными целями обучения.

Заучивание слов - не самая эффективная методика в любых аспектах изучения языка. Нам представляется абсолютно бессмысленным заучивание отдельных слов с их переводом. «Дело в том, что наше мышление ассоциативное, и в памяти остается не слово, а процесс». [2, с.19]. Однако заучивание орфографии специальных терминов полезно для достижения успеха в академических предметах.

Очевидно, что отсутствие полного соответствия между буквами и звуками является источником путаницы и потенциальным препятствием для начинающего читателя. В результате многие учебные заведения приняли иной подход - метод целого текста - "whole-language method" (иначе называемый литературным или управ- ляемым чтением). Стратегия здесь похожа на пословное обучение, однако, существуют принципиальные различия двух методов. Например, студентам предлагают занимательные истории и рекомендуют угадать слова, рассматривая контекст рассказа или подыскивая подсказки в сюжетной линии. При данном подходе также практикуется написание сочинений, что ведет к лучшему запоминанию готовых конструкций.

Метод целого текста преследует цель сделать обучение чтению приятным. Один из его ключевых принципов - никаких фонетических правил. Скорее, связь между буквами и звуками осваивается по мере активной практики чтения. Также при этой методике студентов не перебивают и не исправляют ошибки в процессе чтения. Уникальность этой методики состоит в том, что она признает чтение естественным актом, также как говорение. Как начинающие учатся читать? Хотя многие педагоги и родители убеждены в том, что врожденный интеллект ускоряет приобретение навыков чтения, доказательства говорят об обратном. Два отдельных исследования 1960-х и 1970-х годов показали, что в целом IQ имеет очень мало отношения к ранней способности к чтению. В последнее годы ученые пришли к выводу, что дети, испытывающие трудности с обучением чтению, часто имеют IQ выше среднего.

Если говорить об изучении иностранных языков, среди лингвистов существует мнение о том, что метод целого текста подходит только для обучения детей. По аналогии с тем, как дети начинают говорить, оказавшись в иноязычной среде. Это утверждение нам кажется спорным. Если рассмотреть практику освоения языка взрослыми эмигрантами, то можно прийти к выводу, что метод целого текста как нельзя лучше подходит в данной ситуации. Тут также следует иметь в виду, что опыт чтения книг у взрослого, гораздо больше, чем у ребенка, что способствует приобретению навыка чтения на любом языке. «Практика чтения у взрослого отчасти заменяет легкость, присущую детскому восприятию речи».[3, с.15].

Опыт работы с детьми, как ни парадоксально, также опровергает утверждение об исключительной действенности этого метода в отношении детей. Те дети, которые считались способными к чтению на раннем этапе, часто теряют навыки в подростковом возрасте. И наоборот. Так называемые «неспособные» дети, полюбившие читать книги и, соответственно прошедшие хорошую практику чтения, к подростковому возрасту становятся гораздо более техничными читателями.

Освоение техники чтения на раннем этапе - это залог приобретения глобального жизненного навыка. Поэтому выбор верного образовательного подхода приобретает особую важность. Несмотря на то, что продолжаются споры о том, какой метод наиболее эффективный, 
мы склоняемся к мнению, что для взрослого учащегося, начинающего читать на иностранном языка, наиболее подходящим является смысловой метод. Что это такое?

Во всех трех методиках речь в большей степени идет о технике чтения. Учитывая то, что нашей задачей является выявление взаимосвязи между методами обучения чтению на родном и иностранном языках, нам представляется важным отметить 2 отдельных аспекта чтения: техника чтения и понимание прочитанного. Очевидно, что для второго вида наиболее применим метод целого текста, однако с некоторыми оговорками. Дело в том, что когда ребенок учится читать на родном языке, он на первом этапе может зрительно не узнать слово, смысл которого ему знаком. Эта проблема решается путем вторичного прочтения. При этом студенту, читающему иностранный текст, мешает не только орфография, но и непонимание смысла. Поэтому для того, чтобы научиться понимать прочитанное, на наш взгляд, подходит модифицированный вариант метода целого текста, который мы назвали «смысловым методом».

Прежде чем переходить к описанию смыслового метода, используемого для понимания прочитанного, следует поговорить о понятии «беглость чтения». Беглость также относится к техникам чтения, но одновременно и является мостиком к пониманию. Беглое чтение - это способность читать правильно, в естественном темпе, с соответствующим ритмом, интонацией и выражением. У начинающих чтение неустойчиво и наполнено колебаниями. Они делают фальстарты и ошибки в произношении. Но даже у более опытных учащихся возникают проблемы с беглостью чтения текстов, содержащих много незнакомых слов. Их чтение может замедлиться и характеризоваться большим количеством колебаний и неправильным произношением. Развитие беглости важно, потому что человеческий мозг ограничен в своей способности выполнять много когнитивных функций одновременно. Когда чтение слов и предложений осуществляется автоматически и свободно, читатели могут более полно сосредоточиться на понимании и соединении предложений и абзацев, что позволяет им извлекать смысл из текста. Для всех читателей, даже опытных, беглость зависит от сложности текста и знакомства читателя с его структурой и тематикой.

Беглость чтения может быть измерена с помощью стандартных тестов. Точность чтения - это количество или процент правильно прочитанных слов в тексте. Скорость чтения - это количество слов, прочитанных за определенный промежуток времени, например, количество слов, прочитанных за минуту, или среднее количество слов, прочитанных за минуту.

Другой способ оценить беглость - это ритм. В рамках исследования, проведенного Национальным Центром
Образовательных Экспертиз США, исследователи разработали четырех-бальную шкалу беглости речи, основанную на месте и количестве пауз. Первый уровень на шкале представляет учащихся, которые делают паузы пословно, а четвертый уровень - тех, кто делает только смысловые паузы в конце фраз.

Одним из важных инструментов является повторное чтение, при котором учащийся получает обратную связь в виде выявления и исправления ошибок. Как для сильных, так и для слабых читателей повторное чтение под руководством преподавателя обычно приводит к умеренному увеличению беглости и точности, а иногда и к развитию понимания.

Что такое понимание? Независимо от типа чтения (для работы, для учебы, для удовольствия), целью всегда является понимание. “Чтение - это процесс конструирования значения из письменных текстов. Это сложный навык, требующий координации взаимосвязанных источников информации". [4]. Понимание - активный процесс; читатель взаимодействует с текстом. Чтобы облегчить понимание, опытные читатели используют специальные стратегии. Однако менее опытные читатели часто не осведомлены о стратегиях понимания и не могут разработать их самостоятельно. В результате на прочтение одной статьи уходит очень много времени.

Как мы уже указывали выше, именно беглость чтения подводит нас к данному этапу - пониманию прочитанного, хотя эти понятия лежат в совершенно разных плоскостях. Дело в том, что техники чтения далеко не всегда облегчают понимание прочитанного. Учащийся может выработать отличное произношение и при этом не понимать смысл прочитанного. И наоборот. Студент с плохими техническими навыками быстро и осмысленно читает текст. Но для этого он должен владеть техниками чтения для понимания. И вот тут вступает в действие смысловой метод.

Существует ряд методик, обучающих пониманию прочитанного. Чтобы понять текст, читатель должен расшифровать слова и связать их с их значениями. Степень понимания зависит от того, что читатель может извлечь из текста, основываясь на предыдущих знаниях и прошлом опыте.

Некоторые преподаватели полагают, что сочетание обучения на основе текста и фонетики более эффективно, чем любой из используемых методов в отдельности. Очевидно, что педагогам следует найти баланс. В частности, понимание может пострадать, когда читатели не могут распознавать отдельные слова в тексте. Например, читатель может быть концептуально готов понять текст, но на практике не в состоянии этого сделать, если он не сможет прочитать отдельные слова. Чтение долж- 
но основываться на твердом понимании связей между буквами и звуками. Алфавит, к сожалению, не дает читателям инструменты, необходимые для расшифровки отдельных слов. Чтобы прочитать отдельные слова, нужно обладать фонематической осведомленностью и навыком анализа слов. [5].

Однако способности расшифровывать отдельные слова недостаточно. Читатели также должны уметь быстро распознавать цепочки слов при чтении предложений и более длинных текстов. Свободное чтение имеет решающее значение для адекватного понимания.

Одним из способов, помогающим в рассмотрении всех компонентов программы, является создание профилей чтения. Профиль чтения объединяет информацию из тестов, проводимых с учащимися. Это помогает сформировать представление о сильных и слабых сторонах и потребностях читателя. Такой тест включает в себя отдельную оценку учащегося по каждому основному компоненту чтения. Обобщение результатов дает возможность выбрать верный подход для каждого студента или группы.

Как указывалось ранее, каждый базовый компонент чтения развивается через конкретные практики. Но так же, как все компоненты должны функционировать вместе, чтобы чтение было эффективным, и их изучение должно быть одновременным, чтобы максимизировать эффективность обучения. При очевидной логичности такой программы, она применима, как нам кажется, только в профильных лингвистических ВУЗах.

Однако, вернемся к понятию «смысловой метод», который, с нашей точки зрения, наиболее эффективен для использования взрослыми при изучении чтения с целью понимания прочитанного. Здесь следует обозначить некоторые принципы, на которых он базируется. В данном контексте будет уместно вспомнить «метод погружения» (Immersion method), который давно практикуется в разных странах. «Метод погружения в языковую среду (языковое погружение) - это метод обучения второму (или иностранному языку), при котором само обучение ведется полностью или частично на изучаемом языке». $[6$, c.207] Этот метод прежде всего направлен на развитие навыков говорения. Говорящий погружается в иноязычную среду, где отсутствует понятие перевода слов на родной язык. Здесь можно провести следующую аналогию. В случае обучения чтению смысловым методом учащийся погружается в текст в поисках смысла происходящего, где отдельные незнакомые слова постепенно перестают быть помехой к пониманию.

При смысловом методе, также как и при методе целого текста, работают особые техники чтения, направленные на понимание прочитанного. Прежде всего это skimming and scanning - так называемое «чтение по диагонали».

Скимминг (skimming) используется для быстрого определения основных идей текста. Он выполняется со скоростью в три-четыре раза быстрее, чем при обычном чтении. Есть много стратегий, которые можно использовать при скимминге. Наиболее распространенные - чтение первого и последнего абзаца, использование заголовков и подзаголовков. Также рекомендуется прочитать первое предложение каждого абзаца, если оно несет смысловую нагрузку.

Сканирование (scanning) - это также беглое прочтение текста с целью понимания его сути. Здесь эффективен поиск ключевых слов и предложений. Сканирование используется при быстром поиске необходимого ресурса, при обилии исходного материала.

Для выбора технологий также важно понимать принципиальные отличия интенсивного и экстенсивного чтения.

Экстенсивное чтение - это подход к изучению иностранного языка при большом объеме чтения. Студенты не ищут значение каждого слова, а рассматривают неизвестные слова в определенном контексте, что позволят студенту вывести значение слова и таким образом, понять смысл отрывка. Несмотря на то, что этот подход широко практикуется, его эффективность, тем не менее, оспаривается некоторыми преподавателями. Однако, нам навык контекстуального понимания представляется очень полезным, так как студенты самостоятельно, эмпирическим путем приходят к выводу, что одно и то же слово в разных контекстах может иметь разные значения. Иными словами, такое чтение развивает чувство языка. Также немаловажно, что такой метод мотивирует студентов и позволяет получать удовольствие от чтения.

Экстенсивное чтение во многом способствует успешному освоению иностранного языка:

1. Улучшает общую языковую компетенцию учащихся.

2. Вызывает интерес к языку.

3. Расширяет словарный запас.

4. Способствует улучшению навыков письма.

5. Развивает интерес к чтению.

Интенсивное чтение - это, по сути, глубокое чтение с конкретными учебными целями и задачами. Это чтение с высокой степенью понимания и удержания материала в течение длительного периода времени. Совершенно естественно, что оно предполагает перевод и заучивание незнакомых слов. Так же, как исправление ошибок в речи препятствует речевоспроизведению, заучивание отдельных слов препятствует пониманию целой фразы. В связи с этим такой вид чтения не рекомендован при 
использовании смыслового метода.

И тут необходимо обозначить еще одну область, которой уделяется очень мало внимания. Это мотивация или необходимость и желание научиться читать. Эффективное обучение чтению не может происходить без достаточной мотивации со стороны ученика. Мотивация особенно важна для взрослого, изучающего иностранный язык, потому что, помимо первоначального желания учиться читать, взрослые должны преодолеть множество социально-психологических барьеров, а также выделить время, необходимое для эффективного обучения.
«В результате изменившихся подходов личностно ориентированная парадигма обучения иностранному языку в последнее время претерпела значительные изменения». [7, с.68]. Поскольку разные цели и задачи требуют использования разных стратегий, преподаватели должны помочь учащимся разобраться, когда и почему следует выбирать определенные стратегии, как отслеживать их эффективность и как их корректировать по мере необходимости для достижения цели чтения. В нашем исследовании мы постарались доказать, что для взрослого учащегося, ориентированного на понимание прочитанного, именно смысловой метод наиболее эффективен в процессе обучения чтению.

\section{ЛИТЕРАТУРА}

1. Anne Castles, Kathleen Rastl, Kate Nation. Ending the Reading Wars: Reading Acquisition From Novice to Expert// Psychological Science in the Public Interest. June 11, 2018. - 19 issue - P. 5-51

2. Мельничук М.В., Ненюк Е.А., Алисевич М.В. Инновационные психолингвистические приемы как необходимая составляющая продуктивного обучения иностранному языку // Инновации и инвестиции. - 2014. - №11. - С. 18-21

3. Strucker, J. What silent reading tests alone can't tell you: Two case studies in adult reading differences// Focus on Basics. - 1997. - 1(B). - P. 13-16

4. Turaeva G. Goals and techniques for teaching reading comprehension// Евразийский Научный Журнал. - 2018. - №4

5. Wesley A. Hoove. The Importance of Phonemic Awareness in Learning to Read// SEDL Letter. - December 2002. - Volume XIV, Number 3

6. Вебер, И.С. Метод языкового погружения на уроках английского языка в современной школе / И.С. Вебер. — Текст: непосредственный, электронный // Молодой ученый. — 2019. — № 6 (244). — С. 207-209.

7. Мельничук M.В., Алисевич M.B. Scrum-технологии как инновационный метод обучения иностранному языку в нелингвистическом вузе// Современная наука: актуальные проблемы теории и практики. Серия «Гуманитарные науки» — 2018. — № 4. — C. 68-71



